\title{
Contributions from the South African Society of Psychiatrists (SASOP) to the National Mental Health Action Plan
}

\author{
A B R Janse van Rensburg, MB ChB, DCH, FC Psych (SA), MMed, PhD \\ ${ }^{1}$ South African Society of Psychiatrists, Johannesburg, South Africa \\ ${ }^{2}$ Department of Psychiatry, University of the Witwatersrand, Johannesburg, South Africa
}

Corresponding author: A B R Janse van Rensburg (bernardj@gpg.gov.za)

\begin{abstract}
The national Mental Health Action Plan (MHAP) flowed from the Ekurhuleni Declaration, adopted at the National Mental Health Summit (NMHS) in April 2012. The final draft of the MHAP included eight national objectives, with key activities which were believed to be 'catalytic.' These objectives include: district-based mental health service; institutional capacity; surveillance, research and innovation; infrastructure and capacity; mental health technology, equipment and medicines; inter-sectoral collaboration; human resources; and advocacy, mental health promotion and prevention of illness. A representative group of regional State Employed Special Interest Group (SESIG) delegates met during April 2013, to: operationalise the 12 South African Society of Psychiatrists (SASOP)/SESIG position statements of the previous year; review SASOP's position statements in the context of the proposed national MHAP; and to identify SASOP's role and responsibilities accordingly. This paper describes the contextual events in the drafting of the MHAP, as well as the appraisal of the MHAP during the 2013 SASOP/SESIG meeting, and SASOP'S envisaged role and responsibilities according to the national MHAP.
\end{abstract}

S Afr J Psych 2013;19(4):205-212. DOI:10.7196/SAJP.501

'While there is no health without mental health, there is also no complete mental health without psychiatry.' - SASOP ${ }^{[1]}$

This paper describes events that have contributed to the recent drafting of a national Mental Health Action Plan (MHAP), as well as the South African Society of Psychiatrists (SASOP's) recent engagements with the MHAP. These events include: (i) the National Health Council (NHC's) initiation of the development of a Mental Health Policy Framework and Strategic Plan; ${ }^{[2]}$ (ii) new policy developments by the national Department of Health $(\mathrm{DoH})$ informed by, among others things, consultation and data collected through the Mental Health and Poverty Project (MHaPP); and specifically (iii) the NHC's intention of hosting a National Mental Health Summit (NMHS).

The NMHS was preceded by provincial summits, which aimed to: (i) review the quality and quantity of provincial mental health services; (ii) identify key challenges in the mental healthcare system; (iii) provide information on best practices that had emerged since 1994; and (iv) agree on key interventions to be prioritised and implemented as part of the reorganisation and strengthening of the health system.

These provincial summits were led by provincial members of executive committees (MECs) during February and March 2012. The NMHS followed in April 2012, chaired by the Minister of Health, Dr Aaron Motsoaledi, at the St Georges Hotel in Gauteng. ${ }^{[3]}$ Its theme was 'Scaling up investment in mental health for a long and healthy life for all South Africans. ${ }^{\text {' }]}$ The provincial and national summits were attended by over 4000 delegates overall, comprising representatives of the National Assembly, Provincial Legislatures, government departments, Mental Health Review Boards (MHRBs), non- governmental organisations (NGOs), the World Health Organization (WHO), academic institutions, research organisations, professional bodies, traditional health practitioners, clinicians and advocacy organisations. After three days of deliberations, the NMHS adopted the Ekurhuleni Declaration, which listed the specific commitments by delegates and the consequences for its implementation. ${ }^{[5]}$

Following the NMHS, a task team was established under the stewardship of Deputy Health Minister Gwen Ramakgopa, to develop a strategic action plan for implementing the resolutions from the NMHS and from the draft policy framework. ${ }^{[2]}$ This task team was comprised of the NMHS's organising committee. It was chaired by Prof. S Rataemane, with Prof. C Lund as vice chair. The team met in Pretoria in December 2012 and February 2013 and produced the first draft MHAP, which listed all the key actions identified in the Ekurhuleni Declaration and the draft policy framework. The second draft included eight objectives with 'catalytic' key activities - that is, requiring the most effective resource inputs for the maximum results.

Following further comments from role players and inputs from the NMHS organising committee, a final draft of the MHAP was completed in line with key mental health policy and legislation, including: the South African Constitution; ${ }^{[6]}$ the National Health Act; ${ }^{[7]}$ the Mental Health Care Act; ${ }^{[8]}$ the Criminal Procedure Act; ${ }^{[9]}$ the Children's and Child Justice Act; ${ }^{[10]}$ and the Prevention and Treatment of Substance Dependency Act. ${ }^{[1]}$ The final draft MHAP also took cognizance of the National Service Delivery Agreement, ${ }^{[12]}$ the Integrated School Health Policy, ${ }^{[13]}$ the National Development Plan, ${ }^{[14]}$ the Human Resources Strategy ${ }^{[15]}$ the Non-Communicable Diseases Strategy, ${ }^{[16]}$ the National Drug Master Plan, ${ }^{[17]}$ and the National Strategic Plan on HIV, Sexually Transmitted Infections (STIs) and TB ${ }^{[18]}$ Lastly, the MHAP was aligned 
with the activities regarding the planned national health insurance (NHI) system. ${ }^{[19]}$ The final MHAP draft was scheduled for submission to the NHC, and expected to be approved in the second half of 2013. At time of going to print the document had not been officially released.

Immediately before the NMHS, SASOP consulted its constituents in the first SASOP/State Employed Special Interest Group (SESIG) strategic planning meeting, held from 30 March to 1 April 2012 in Windhoek. The result was 12 position statements on psychiatric care in the public sector. ${ }^{[1]}$ In December 2012, when the Deputy Minister's task team invited SASOP to provide inputs into the development of the national MHAP, SASOP took this meeting into account, as wells as the following introductory statements in its submission:

- 'The SASOP acknowledges and values the invitation and opportunity to participate in the technical consultative meeting to develop a national mental health action plan and to set targets and specify activities, based on the declaration adopted by participants at the NMHS in April 2012.

- 'The SASOP had consulted its constituency in March/April 2012 in preparation for its participation in the NMHS. Twelve SASOP position statements were formulated as a result, which were subsequently (August 2012) published as a supplement to The South African Journal of Psychiatry. ${ }^{[1]}$

- 'The SASOP endorses the Ekurhuleni Declaration on Mental Health of April 2012, as an active participant in the NMHS on 11 and 12 April 2012, as well as the process of the development of national mental health policy. ${ }^{[4-5]}$

- 'While mental health is currently included in the structure of the DoH as a component of the sub-programme Non-Communicable Diseases of Programme 4 (i.e. Primary Healthcare Services), mental health and psychiatric services is understood to also be an integrated component of Programmes 2 (i.e. Health Planning and Systems Enablement), 5 (i.e. Hospitals, Tertiary Services and Workforce Development) and 6 (i.e. Health Regulation and Compliance Management).

- 'These (preceding) SASOP comments were made in cognizance of a range of existing departmental policy documents and action plans. ${ }^{[16,18,20-24]}$

Another group of representative state-employed delegates from the seven SASOP sub-groups was invited to participate in the 2nd SASOP/SESIG strategic weekend meeting, from 12 to 14 April 2013, at Oubaai Resort in George. The meeting's main objectives were: $(i)$ to operationalise the 12 SASOP/SESIG position statements to derive action plans, indicators and time frames for implementation on a regional and national level for the current two-year term of 2012 - 2014; and (ii) to conduct a public/private sector consensus meeting on the previously proposed SASOP treatment guidelines, as addressed by the 4th SASOP position statement on standard treatment guidelines (STGs) and essential drug lists (EDLs). The meeting also aimed to identify specific catalytic points, as advised by the Deputy Minister in her opening address at the 17th National SASOP Congress in September 2012, and during SASOP's meeting with her in February 2013. The Deputy Minister also recommended that SASOP review its position statements in context of the proposed national MHAP and identify its role and responsibilities accordingly.

\section{Appraisal of the MHAP at the 2013 SASOP/SESIG meeting}

During the 2nd SASOP/SESIG strategic weekend meeting, the eight objectives of the final draft of the national MHAP were considered in the light of the relevant SASOP position statements (PSs). Four sessions were dedicated respectively to:

- SASOP/SESIG structure and organisation: SASOP PS1 on national mental health policy, PS2 on psychiatry and mental health, and PS10 on the specialty status of psychiatry

- Systems, facilities, infrastructure and resources: PS3 on infrastructure and resources; PS7 on community psychiatry and referrals; PS8 on recovery and integration; and PS12 on security in psychiatric hospitals and units

- Algorithms for the treatment of psychiatric disorders: PS4 on standard treatment guidelines and essential drug lists

- Special interest areas: PS5a and 5b on HIV/AIDS in children and adults; PS6 on substance abuse and addiction; PS9 on culture, mental health and psychiatry; and PS11a on forensic observations; PS11b on state patients; and PS11c on mentally ill prisoners.

The following paragraphs summarise these deliberations, as well as the comments (italicised) submitted by the SASOP Board of Directors to the Deputy Minister's task team in December 2012. All comments must be understood to include child, adolescent and geriatric psychiatric services.

\section{Objective 1: District-based mental health services and primary healthcare re-engineering (Table 1)}

- SASOP and the psychiatrists in its various sub-group regions should be part of the piloting of the NHI in each identified district, as well as of the NHI's proposed district clinical specialist support structures. This participation should include the definition and designation of services, referral guidelines between levels of services and the allocation of responsibilities. In view of the reality that there are currently not enough psychiatrists, appropriate task shifting can be supported, with psychiatrists involved in training, supervision and specialist support services.

- The process of integrating mental health into primary care has thus far been misinterpreted. Teams of designated community mental health nurses were dismantled in order to be 'integrated' into primary care. It must be emphasised that the integration of mental health services should not mean the dismantling of expert mental health teams.

- Community psychiatrists or psychiatrists who take a public health approach should be the leaders of these multidisciplinary mental healthcare teams (MDTs). Other members must include a general medical practitioner, a (community) psychologist, a nursing professional, a suitably trained social worker with experience in psychiatry, and an occupational therapist (OT) with experience in psychiatry.

- There could also be public/private partnerships in this regard, remunerating private practitioners for work done for the district services. District services could act as the training platform for staff performing their community service, under the supervision of the specialist MDT members.

- The objective of strong integrated district mental health teams and skilled general practitioners in primary healthcare should provide 
a further incentive to ensure adequate medical intern training in psychiatry, and to extend the current internship training to a two- to three-month rotation.

- Mental health and psychiatric services and the resources required on a primary-care level must be clearly defined, e.g. managing a 72-hour assessment facility in a district hospital may be the responsibility of a general medical practitioner (medical officer) with an interest in psychiatry. However, offering this service in district hospitals will require designated psychiatric beds according to appropriate norms and standards for this level of care. This will also require clear guidelines for referral between primary district mental health services and specialist inpatient services on secondary and tertiary levels of care (see Objective 4).

- Although community-based services are recommended - of which the district hospital is a component in the referral system - flexible co-operation and effective communication with the secondary and tertiary levels of services must be established through, for example, regular liaison meetings and appropriate community outreach activities from these secondary and tertiary facilities in their different designated catchment areas. ${ }^{[25-27]}$

- Appropriate structures and line-function channels must be ensured for effective communication, participation and liaison between provincial departments of health head offices, provincial mental health structures, hospital services and district health services. These must allow for the participation of individual psychiatrists and other professionals, and for participation through their representative professional societies (e.g. SASOP).

\section{Objective 2: Institutional capacity (Table 2)}

- It is important to ensure adequate structures and channels for psychiatrists to be incorporated at all the levels of decision-making: facility, district, provincial and national.

- Psychiatry and mental health services generally fall through the cracks of national and provincial planning. For example, in the national or provincial directorates of mental health, planners and managers do not currently know what services psychiatrists are or should be rendering, or current needs. Often, mental health services and facilities are operated with no, or only very limited, inputs from a psychiatrist. Liaison in this regard should include, for example, quarterly meetings between SASOP national structures and the office of the Deputy Minister of Health, as well as the Department of Health's Cluster Head and the Directorate of Mental Health.

- Psychiatrists who take a public health approach must be included in the structures of national and provincial mental health directorates, and be given sufficient seniority to influence policy decisions and budget allocations.

- Mental health directorates must be established in all provinces and include psychiatrists of adequate seniority, who can make an effective impact on the management of services. Liaison on a provincial level should include, for example, quarterly meetings between SASOP's regional structures, MECs, and provincial departments of health/directorates of mental health.

- Currently the designation of a facility as secondary, tertiary, or specialised determines its budget and staff allocation, including the seniority of its chief executive officer (CEO). The process of designating facilities must be reviewed to consider the actual level

and content of services rendered. For example, academic activities such as teaching and research, defined as tertiary, also occur at psychiatric hospitals, which are usually designated as specialised hospitals and thus lack tertiary hospital staff structures and are excluded from tertiary budget allocations such as the National Tertiary Service Grant.

- As a point of departure, SASOP would like to see the establishment of fully constituted MHRBs in all areas, with the information technology capacity to effectively monitor and track the admission and discharge of users from facilities and services. The MHRBs should engage in a good, co-operative and ethical working relationship with mental health practitioners. ${ }^{[28,29]}$

\section{Objective 3: Surveillance, research and innovation (Table 3)}

- Structures and channels should be established for psychiatrists, individually or through SASOP, to participate in all monitoring and evaluation processes (facility, provincial and national).

- The inclusion of psychiatrists in the process of strategic and operational planning of mental health services at all levels should also include the proposed district clinical specialist support structures for the implementation of the NHI in the provisional 10 identified districts, as well as in later phases of implementation (see Objective 1).

- Psychiatrists, individually and collectively through SASOP, should be invited to establish the research agenda for psychiatry and mental health. SASOP can participate through its different special interest groups, which include: Substance Abuse and Addiction Disorders; HIV/AIDS and Neuropsychiatry; Biological Psychiatry; Child and Adolescent Psychiatry; Geriatric Psychiatry; Social Psychiatry; Spirituality (religion and culture) and Psychiatry; and Forensic Psychiatry.

Table 1. National Objective 1: District based mental health services and primary healthcare re-engineering (initial focus on NHI pilot sites)

\begin{tabular}{ll}
\hline Key activities & $\begin{array}{l}\text { Corresponding SASOP } \\
\text { position statements }\end{array}$ \\
\hline $\begin{array}{l}\text { At least one specialist mental health team } \\
\text { will be established in each district }\end{array}$ & $\begin{array}{l}\text { SASOP PS7 on } \\
\text { community psychiatry }\end{array}$ \\
$\begin{array}{l}\text { Selected community health centres and } \\
\text { clinics will be designated to provide }\end{array}$ & $\begin{array}{l}\text { and referrals } \\
\text { psychological services with appropriate }\end{array}$ \\
$\begin{array}{l}\text { accreditation and staffing } \\
\text { and integration }\end{array}$
\end{tabular}

NHI = national health insurance.

Table 2. National Objective 2: Institutional capacity (national, provincial, district)

Key activities

Establish a national mental health

Technical Committee (in terms of Section

71 of the MHCA)

Establish mental health directorates in each of the 9 provinces

Establish functioning review boards in all provinces, in line with the MHCA

MHCA = Mental Health Care Act of 2002. 
- Minimum data sets including appropriate demographic and clinical variables will be essential, as will the capacity at the different levels and hospitals/services to accurately collect, collate, analyse and report on the data from different areas.

- It is strongly recommended that appropriate partnerships should be developed with non-governmental agencies (NGOs and privatesector bodies) with expertise in adequate information systems and surveillance.

- The role of health, mental health and in particular psychiatry as part of a comprehensive approach to substance abuse and addiction needs to be emphasised. Psychiatrists are well-positioned to involve other health practitioners and medical specialists who often need to be consulted in the management of these patients (from detoxification to rehabilitation), as well as treating patients with 'dual-diagnosis' with the appropriate services/facilities.

- With regard to culture, religion and psychiatry, care must be taken not to elevate the status of one religious/healing group above others, as there are many groups which all have concepts on health, healing, culture and spirituality. More discussion and debate is required, as the role of faith traditions and belief systems in health and mental health can't be disregarded, while in relation to and in comparison with a scientific perspective, it can't be considered on an equal basis.

- Religious beliefs are e.g. often incorporated into delusional systems and can prevent patients from developing insight into their psychological functioning and psychiatric illness. Religious ideas are often in conflict with scientifically valid, evidence-based treatments, and frequently diametrically opposed to them.

- Conversely, religious convictions are often useful and healthpromoting, and should not be discarded out of hand. These should form part of a bio-psycho-social approach and be part of a recovery-focused model. Psychiatrists should incorporate spiritual/religious matters as part of a bio-psycho-social model, just as spiritual/religious workers should give credence to the biological aspects of treatment

- It is SASOP's opinion that if we want to commit to evidence-based interventions, this commitment has to apply to all models equally.

- Every discipline should then be equally regarded in terms of regulation of training and ethical standards of practice.

\section{Objective 4: Infrastructure and capacity of health facilities (Table 4)}

- It is SASOP's position that psychiatrists should be part of the development of task teams on all levels (e.g. task teams on the review of the status of existing health facilities).

- Each level of health service (primary, secondary and tertiary) must have infrastructure suited for the particular level required: primary and community care clinics, district hospitals, regional hospitals, tertiary hospitals, central hospitals, and psychiatric/specialised hospitals. Existing national norms and standards must be reviewed to adequately reflect the situation on different service levels and for identified service packages, including community residential facilities.

- Clarity is required on the content of these services and the level of expertise expected in the different levels of services (see Objective 1).

- With reference to the current example of the Kimberley Psychiatric Hospital complex, we express concern about existing or future capital projects of large centralised hospitals with apparent disregard for the principles of an integrated, community-based model and with the potential to take up the entire allocated budget for an area or service, with no provision for recurrent costs such as the appointment of staff and operational cost items.

- Rather than building large hospitals (e.g. the Kimberley Psychiatric Hospital project and the proposed facility in Mpumalanga Province), a community-based model should be implemented.

Table 3. Objective 3: Surveillance, research and innovation

\begin{tabular}{|c|c|}
\hline Key activities & $\begin{array}{l}\text { Corresponding SASOP } \\
\text { position statements }\end{array}$ \\
\hline \multirow{2}{*}{$\begin{array}{l}\text { Ensure the accurate collection and use of } \\
\text { the minimum dataset for mental health } \\
\text { that is integrated into the general health } \\
\text { information system at all levels }\end{array}$} & $\begin{array}{l}\text { SASOP PS2 on psychiatry } \\
\text { and mental health }\end{array}$ \\
\hline & $\begin{array}{l}\text { SASOP PS6 on substance } \\
\text { abuse and addiction }\end{array}$ \\
\hline $\begin{array}{l}\text { A national mental health research agenda } \\
\text { will be established to meet national } \\
\text { priorities and submitted to the National } \\
\text { Health Research Council }\end{array}$ & $\begin{array}{l}\text { SASOP PS5(a) on HIV/ } \\
\text { AIDS in children; SASOP } \\
\text { PS 5(b) on HIV/AIDS in } \\
\text { adults }\end{array}$ \\
\hline $\begin{array}{l}\text { Develop and implement a monitoring and } \\
\text { evaluation system to track and report on } \\
\text { the implementation of the health sector } \\
\text { drug master plan }\end{array}$ & $\begin{array}{l}\text { SASOP PS9 on culture, } \\
\text { mental health and } \\
\text { psychiatry }\end{array}$ \\
\hline
\end{tabular}

Table 4. Objective 4: Infrastructure and capacity of facilities

\begin{tabular}{ll}
\hline Key activities & $\begin{array}{l}\text { Corresponding SASOP } \\
\text { position statements }\end{array}$ \\
\hline
\end{tabular}

Build/attach mental health inpatient units to designated district and regional hospitals (for emergency admissions, 72-hour assessments, care, treatment and rehabilitation of voluntary, assisted and involuntary mental health users). Design specifications should comply with the Mental Health Care Act

Establish a specialised psychiatric hospital in Mpumalanga Province with the capacity to conduct forensic evaluations, admit state patients and mentally ill prisoners, voluntary, assisted and involuntary mental health users

Revitalise dilapidated mental health facilities in all provinces

Develop community residential care facilities (including halfway houses, assisted living and group homes) to provide accommodation for de-institutionalised service users, in line with national community-based care norms

Equip designated clinics and community health centres with psychology infrastructure (private consulting rooms and group facilitation rooms) where psychologists deliver services
SASOP PS3 on infrastructure and resources

SASOP PS11(a) on forensic observations; SASOP PS 11(b) on state patients; SASOP PS11(c) on mentally ill prisoners

SASOP PS12 on security in psychiatric hospital units 
Alternatively, acute inpatient units in regional hospitals should be considered. Capital projects should be appropriate to the needs of the community they serve. Budgets must also provide for continuous maintenance as well as for the gradual improvement of standards.

- It can be argued that some designated psychiatric beds are required in a district hospital, for example, for 72-hour assessments. As noted above, it must be made clear whose responsibility it is to provide these services, e.g. a general medical practitioner or a specialist. The role of other members of the MDT in a district hospital context must also be clarified. A mental health unit was recently constructed in a district hospital in the Western Cape, which can serve as an example of the requirements for such units.

- Safe medical facilities in general hospitals should include low-, medium- or high-security areas to accommodate restless medically ill (delirious) patients.

- The reviewing of facilities for refurbishment in the different regions should also include existing inpatient units at regional and tertiary hospitals. Norms and standards for such acute units should be standardised and made available to provincial and local planners.

- A core component of infrastructure and capacity for mental healthcare are community-based residential care and psychosocial rehabilitation centres. The responsibility of the different intersectoral role players in this regard must be clarified, e.g. the respective responsibility of the Department of Social Development (DSD) and the DoH.

- There should also be a capital budget for the development of community-based residential care facilities and rehabilitation centres (providing active occupational therapy programmes and employment projects) and not only, as currently, the salaries of social workers. The salaries and equipment of a complete communitybased psycho-social rehabilitation team should be considered, including community OTs, nurses and social workers. Norms and standards for these residential facilities and rehabilitation centres need to be established where necessary or updated.

- Requirements for the licensing of private sector hospitals need to provide guidelines for psychiatric beds for voluntary and nonvoluntary (assisted and involuntary) users.

- Child and adolescent and geriatric services must be included in the planning of the proposed Mpumalanga facility, as they should be in all planning, especially as $80 \%$ of child and adolescent services are rendered by general psychiatry.

- Forensic services must be reviewed, preferably through an interdepartmental committee comprising the departments of health, justice and social development. Psychiatrists must form part of such a structure.

\section{Objective 5: Mental health technology, equipment and medicines (Table 5)}

- SASOP's PS4 on standard STGs and EDLs states that:

- There should be close collaboration and co-ordination between the processes of establishing SASOP and national STGs, and the related decisions on EDLs for different levels.

- This close collaboration will also require liaison with private sector practitioners.
- It can also be suggested that the authors of the SASOP STGs (who followed a formal peer-review process ${ }^{[30]}$ and the National EDL Committee should form a standing committee and/or other structures for ongoing liaison to explore procedural issues, as well as the current and ongoing revision of the different lists of available drugs.

- If, however, EDLs were finalised without such close collaboration and co-ordination in the EDL and STG processes, SASOP will have to express its grave concern, since psychiatry as a specialist clinical discipline will be prejudiced against, while the availability of evidence-based medications will be threatened, particularly in the public sector.

- Over the past 10 years, SASOP has been developing treatment guidelines and algorithms for a range of psychiatric disorders, including attention deficit hyperactivity disorder, major depressive disorder, bipolar mood disorder, schizophrenia, dementia and the various anxiety disorders. These draft SASOP Treatment Guidelines were proposed during the second SASOP/ SESIG strategic workshop, at a consensus meeting attended by over 100 representatives of both public and private sector psychiatrists in the different SASOP regional sub-groups, and approved as current best practice by the delegates and session chairs. It was agreed that the SASOP Treatment Guidelines document would be finalised and published during the subsequent six months, and these guidelines duly appeared in the previous issue of the SAJP. ${ }^{[30]}$

- In existing EDLs, the different prescriber levels should be reviewed in light of the availability of safer and cheaper medications (e.g. serotonin re-uptake inhibitors and second-generation antipsychotics to be prescribed by general practitioners).

- Facilities and equipment for electroconvulsive therapy (ECT) treatment should be included in the scope of the national objective on available equipment.

- Clinics and health centres should be provided with equipment for all the MDT members (psychologists as well as OTs) where they deliver services.

- In considering the rendering of services in the community clinics, provision should be made for transport and travel costs.

- Appropriate access to diagnostic imaging facilities should be ensured, where clinically indicated, and where these investigations would form part of an approved research agenda.

Table 5. Objective 5: Mental health technology, equipment and medicines

\begin{tabular}{ll}
\hline Key activities & $\begin{array}{l}\text { Corresponding SASOP } \\
\text { position statements }\end{array}$ \\
\hline $\begin{array}{l}\text { Make all psychotropic medicines, as } \\
\text { provided on the EDL available at all levels } \\
\text { of care, including PHC clinics }\end{array}$ & $\begin{array}{l}\text { SASOP PS4 on STGs and } \\
\text { EDL }\end{array}$ \\
$\begin{array}{l}\text { Equip clinics and health centres with } \\
\text { psychology equipment (psychological } \\
\text { assessment instruments) where } \\
\text { psychologists deliver services }\end{array}$ \\
EDL = essential drugs list; PHC = primary healthcare; STG = standard treatment guidelines.
\end{tabular}


Objective 6: Intersectoral collaboration (Table 6)

- Examples of cases in psychiatry where intersectoral collaboration is central include: community-based residential and psycho-social rehabilitation facilities and services; forensic psychiatry; substance abuse and addiction; ${ }^{[31,32]}$ child and adolescent psychiatry, and geriatric psychiatry. ${ }^{[33]}$

\section{Objective 7: Human resources for mental health (Table 7)}

- It must be emphasised that mental healthcare services cannot be realised without psychiatric services, and the implied adequate post structures and appropriate levels of seniority for general practitioners, general psychiatrists and sub-specialists (e.g. child and adolescent and forensic psychiatrists).

- Existing national human resources (HR) norms and standards must be reviewed to adequately reflect the situation at different service levels.

- Funding packages should provide adequately for appropriate multidisciplinary services and HR packages, as per provincial strategic plans.

- When planning and funding mental health services, cognisance must be taken of joint-appointee psychiatric specialists' responsibility for 70:30 ratio of service: training (teaching and research) activities. Due consideration should be given to providing for training as per financial package provision.

- It is imperative that medical interns rotate through psychiatric units (in general hospitals) and not only/primarily through mental health/ family medicine services.

- Task shifting may include having the mental health team take some responsibility for training community mental health workers in the district (see Objective 1). The rotating of community service staff (e.g. doctors/psychologists) is important: if the districts become a training platform, community staff will be doing work in the community as a placement.

- The Mental Health Policy mentions district services and provincial and designated psychiatric services, ${ }^{[2]}$ but not central hospitals, where most sub-specialty services are based. Sub-specialty services must be included in the scope of facility, HR and equipment planning. As part of its guidelines on treatment pathways, SASOP should also consider models on the use and scope of, and referral to, the different psychiatric sub-specialists. Posts for sub-specialists must therefore also be considered, as well as primary care structures and tertiary care requirements.

- It can be argued that skills in an African language must be included in the training curriculum of psychiatrists.

\section{Objective 8: Advocacy, mental health promotion and prevention of mental illness (Table 8)}

- Suicide risk assessment must be made a core competency of all medical practitioners, specifically identifying people at risk and the correct management thereof. ${ }^{[34-36]}$

- Systems must be strengthened for the detection and management of child and adolescent mental disorders in schools and the referral to mental health and psychiatric services where appropriate, aligned with the pertaining school health policy. ${ }^{[37,38]}$

- Professional bodies such as SASOP should be involved in the development of advocacy and educational programmes as well as in evaluating their outcomes.
- Considering SASOP's vision, that 'There is no complete mental health without Psychiatry, the society should be regarded as a resource in mental health, to talk to about different aspects of service delivery and treatment options.

- It can be proposed that all mental healthcare facilities must have a programme of mental healthcare user advocacy and must develop consumer support groups.

- One particular preventive activity to be considered is a comprehensive programme to generally improve and strengthen parenting skills. These parenting programmes should be freely accessible and also involve mental health professionals and psychiatrists. From a child and adolescent psychiatry perspective, improving parenting is one of the most important preventive interventions that can be undertaken, with an existing, documented evidence base for its role in the prevention of criminality and substance abuse.

\section{Table 6. Objective 6: Intersectoral collaboration}

Key activity
Mental health will be included on the agenda and mental health rep-
resentation will be assured on the newly established National Health
Commission

Table 7. Objective 7: Human resources for mental health

\begin{tabular}{ll}
\hline Key activities & $\begin{array}{l}\text { Corresponding SASOP } \\
\text { position statements }\end{array}$ \\
\cline { 1 - 2 } $\begin{array}{l}\text { Training health professionals (including } \\
\text { medical interns, nurses and pharmacists) }\end{array}$ & $\begin{array}{l}\text { SASOP PS2 on psychiatry } \\
\text { and mental health }\end{array}$ \\
$\begin{array}{l}\text { will rotate through psychiatric units in } \\
\text { district and regional general hospitals }\end{array}$ & $\begin{array}{l}\text { SASOP PS3 on } \\
\text { infrastructure and } \\
\text { Selected key staff in every primary health } \\
\text { facility will receive basic mental health } \\
\text { training using PC101, and ongoing routine } \\
\text { supervision and mentoring }\end{array}$ \\
$\begin{array}{l}\text { The language competency of all mental } \\
\text { health professionals will be improved, } \\
\text { particularly indigenous African languages }\end{array}$ &
\end{tabular}

Table 8. Objective 8: Advocacy, mental health promotion and prevention of mental illness

\begin{tabular}{ll} 
Key activities & $\begin{array}{l}\text { Corresponding SASOP } \\
\text { position statements }\end{array}$ \\
\hline $\begin{array}{l}\text { A national education programme } \\
\text { for mental health will be established, } \\
\text { addressing knowledge about mental health } \\
\text { and illness; stigma and discrimination } \\
\text { against people with mental illness; and } \\
\text { available services, including suicide } \\
\text { help lines. This will include exposure } \\
\text { to positive images of mental health } \\
\text { advocates, prominent user role models and } \\
\text { well-known and influential champions } \\
\text { for mental health in order to change } \\
\text { discriminatory attitudes toward mental } \\
\text { disability }\end{array}$
\end{tabular}


- Preventive programmes should also be developed regarding interpersonal violence and abuse.

\section{SASOP'S role and responsibilities according to the national MHAP}

The second SASOP/SESIG strategic weekend meeting aimed to (i) operationalise the 12 SASOP/SESIG position statements of the previous year, to derive action plans, indicators and time frames for implementation on a regional and national level; and (ii) review these position statements in the context of the proposed national MHAP, to identify SASOP's role and responsibilities accordingly.

\section{SASOP's position statements and the national MHAP}

Considering its scope and detail, the national MHAP provides an adequate initial framework for action and allows all mental health role players to consider their various priority activities for the short to medium term. It also compels SASOP to align its own strategic action with this framework. However, to implementation of the MHAP will still require government to make specific budget allocations, to achieve the set national and provincial objectives within specified time frames. If the MHAP is not clearly linked to realistic cost estimates, adequate budget allocations, fixed time frames for implementation, and an effective process of evaluating progress and outcomes, it will be doubtful if the MHAP will achieve much in practice, despite very good intentions. Its implementation and monitoring will require effective administrative and information support systems on finances, human resource and equipment/medication. A very clear statement and commitment of responsibility will also be required, for example, on what level of government, and which managers of what programmes, will be responsible for achieving the different key activities.

In particular, the SASOP Board of Directors will be responsible for the implementation on a national level of PS1 on national mental health policy; PS2 on psychiatry and mental health; and PS10 on the specialty status of psychiatry. According to PS1, SASOP will continue to play an active role in the development and implementation of national and regional mental health policy. PS2 may, in this context, also function as the SASOP mission statement for this period, namely:

'To facilitate the situation where psychiatrists are playing a central role, along with the other mental health disciplines, in the strategic and operational planning of mental health services at a local, provincial and national level. This situation will allow for specific time frames, definitions of care at different levels, norms and standards of care, resources to be allocated, as well as the routine monitoring and auditing of mental healthcare programmes to be established in conjunction with psychiatrists on all levels. ${ }^{[1]}$

In terms of the specialty status of psychiatry (PS10), SASOP's main business remains to promote, maintain and protect the honour and interest of its members and of the discipline of psychiatry as a medical specialty. The board will continue to pursue the following outcomes:

- Restorating the academic status of psychiatry as one of the five major clinical disciplines in all South Africa schools of clinical medicine.

- Creation of appropriate management structures for psychiatrists on all levels to ensure that psychiatrists themselves supervise and manage psychiatric services.
- Extension of the training of medical interns in psychiatry to at least two months within the different departments of psychiatry and not as a sub-programme of family medicine.

- Creation of appropriate structures and posts on the appropriate levels for psychiatric sub-specialists, including child and adolescent, geriatric, addiction, consultation-liaison, neuropsychiatry and forensic psychiatry.

\section{Operationalisation of SASOP/SESIG position statements}

As required for the national MHAP, clear statements and commitments must be achieved regarding who within SASOP will be responsible for achieving the society's own objectives. For example, implementing SASOP's 12 position statements and translating them into SASOP's national and regional action plans may require some restructuring of SASOP's national and regional structures. A clear implementation process will also be required, specifying a typical planning cycle in terms of time frames, resources and outcome evaluation.

A strong national SESIG Committee, consisting of regional SESIG representatives and chaired by the national SESIG convenor, will have to be developed. This committee will be responsible for liaison with role players on a national level, e.g. the national DoH and South African Medical Association (SAMA), as well as the co-ordination of the regional implementation of the SASOP/SESIG action plans. This committee should also compile routine reports on the progress of the implementation of SASOP action plans nationally, based on the inputs from the different regions. In addition, it can be envisaged that the different chairs of the regional SASOP sub-groups will be co-responsible for the regional implementation of SASOP/SESIG action plans in SASOP's existing seven regions: Eastern Cape; Free State; KwaZuluNatal; Limpopo; Northern Gauteng; Southern Gauteng and Western Cape. Routine regional reports for submission to the national SESIG Committee will be required. The various convenors of special interest groups will also be required to operationalise SASOP/SESIG PSs in each specific field of interest, which may overlap with the state sector group. For example: substance abuse and addiction disorders; HIV/AIDS and neuropsychiatry; biological psychiatry; child and adolescent psychiatry; geriatric psychiatry; social psychiatry; spirituality and psychiatry; and forensic psychiatry.

Regarding the specific terms of reference for the implementation of SASOP action plans, nationally and regionally, it is proposed that the steps of a typical annual planning cycle can translate the 12 SASOP/ SESIG PSs into action plans. These steps include:

- Step 1 - state of affairs/re-evaluation

- Step 2 - needs assessment

- Step 3 - objectives and targets (outcomes)

- Step 4 - implementation (Fig. 1).

During Step 1, information will be collected and collated on: (i) the population in a particular region; (ii) the context of current service provision; (iii) current utilisation of services; (iv) consultation with role players, including users; $(v)$ current available resources, including facilities, human resources; and ( $v i$ ) current expenditure on services.

A needs assessment and estimation of the cost of services proposed for the new term of implementation will be conducted during Step 2, referring to existing policy and set norms and standards for HR, facilities and the population's mental health status. Values for service 


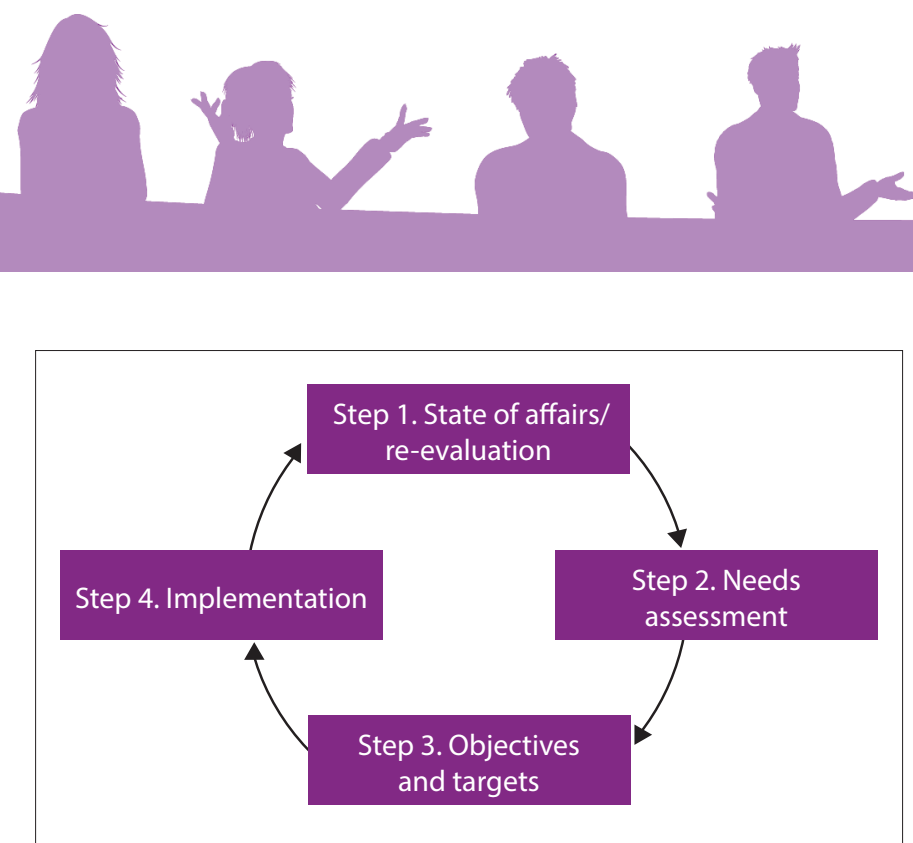

Fig 1. Continuous strategic planning cycle.

delivery will be determined and indicators to measure progress with implementation will be identified.

During Step 3 objectives and targets (outcomes) will be set in terms of SASOP's vision and mission. Action plans will be developed specifying priorities, responsibilities and time frames for evaluation.

During the implementation phase (Step 4), progress will be monitored according to the identified indicators and available budgets will be managed. The different outcomes will be evaluated at the end of the planning cycle, signalling the point of departure for the new cycle.

Thus the data collection and collation process required for regular regional and national reporting on SASOP action plans will concur with data required for the implementation of the national MHAP. Areas covered will include: the facility audit of public and private units/services and capacity in terms of the national MHAP (National Objective 4); drug availability on national and regional EDLs (National Objective 5); and a human resource audit in terms of the national MHAP (National Objective 7), as stated in the final MHAP draft. Considering SASOP's position statements in this manner, within the context of the proposed national MHAP, will position SASOP to fulfil its strategic national and regional role and responsibilities accordingly.

Acknowledgments. Thanks to C Lund, Director of the Alan J Flisher Centre for Public Mental Health, Department of Psychiatry and Mental Health, University of Cape Town, for presenting and facilitating the discussion on the national mental health action plan during the second SASOP/ SESIG strategic weekend meeting. Thanks also for the participation and contributions by regional SESIG delegates: $S$ van Wyk, Z Zingela, M Nagdee (Eastern Cape); I Westmore (Free State); J Burns, T Madigoe, E Karim (KZN); G Grobler, C Mataboge, R Mataboge, W van Staden (Northern Gauteng); M Talatala, Y Jeenah, Y Moosa, M Motlana, P Naicker, A Pillay, L Robertson, U Subramaney, M Ewart-Smith (Southern Gauteng); R Allen, D Stein, S Hawkridge, L Koen, P Milligan, D Niehaus, W van Rooy, J Parker, F Potocnik (Western Cape).

\section{References}

1. Janse van Rensburg B. The South African Society of Psychiatrists (SASOP) and SASOP State Employed Special Interest Group (SESIG) Position Statements on Psychiatric Care in the Public Sector. South African Journal of Psychiatry 2012;18(3):133-148. [http://dx.doi.org/10.7196/SAJP.374]

2. South African Department of Health. Mental Health Policy Framework for South Africa and Strategic Plan 2014 - 2020 (Final Draft). Pretoria: Government Printer, 2012.

3. Motsoaledi AP. Address of the Minister of Health at the National Mental Health Summit, 12 April 2012, St Georges Hotel, Gauteng. http://www.doh.gov.za/show.php?id=3505 (accessed 8 October 2013).

4. National Mental Health Summit, 12 - 13 April 2012. Proceedings. http://www.doh.gov.za/eventlist. php?eid=15 (accessed 26 November 2012)
5. National Mental Health Summit, 12-13 April 2012. The Ekurhuleni Declaration on Mental Health. African Journal of Psychiatry 2012;15:381-383

6. South African Government. The Constitution of the Republic of South Africa, Act No. 108 of 1996 Pretoria: Government Printer, 1996.

7. South African Government. National Health Act, No. 61 of 2003. Pretoria: Government Printer, 2003.

8. South African Government. Mental Health Care Act, No. 17 of 2002. Pretoria, Government Printer, 2004.

9. South African Government. Criminal Procedure Act, No. 51 of 1977. Pretoria: Government Printer, 1977.

10. South African Government. Child Justice Act, No. 75 of 2008. Pretoria: Government Printer, 2009.

11. South African Government. Prevention and Treatment of Drug Dependency Act, No. 20 of 1992. Pretoria: Government Printer, 1992.

12. South African Department of Health. National Service Delivery Agreement. Pretoria: Government Printer, 2010. http://www.doh.gov.za/docs/misc/2010/delivery_agreement.pdf (accessed 24 September 2013).

13. South African Department of Health. Integrated School Health Policy. Pretoria: Government Printer, 2012. http://www.doh.gov.za/docs/policy/2012/Integrated_School_Health_Policy.pdf (accessed 24 September 2013).

14. National Planning Commission. National Development Plan. Pretoria: Government Printer, 2011. http://www.npconline.co.za/medialib/downloads/home/NPC\%20National\%20Development\%20 Plan\%20Vision\%202030\%20-lo-res.pdf (accessed 24 September 2013).

15. South African Department of Health. Human Resources Strategy. Pretoria: Government Printer, 2012. http://www.doh.gov.za/docs/stratdocs/2012/hrhstrat.pdf (accessed 24 Sep 2013).

16. South African Department of Health. Non Communicable Diseases Strategy. Pretoria: Government Printer, 2013. http://www.doh.gov.za/docs/webcontent/2013/Non-Communicable_Diseases_progress. pdf (accessed 24 September 2013)

17. South African Department of Health. National Drug Master Plan. Pretoria: Government Printer, 2012 http://www.doh.gov.za/docs/stratdocs/2012/Mini_Drug_Master_Plan.pdf (accessed 24 September 2013).

18. South African Department of Health. National Strategic Plan on HIV, Sexual Transmitted Infections (STI) and TB. Pretoria: Government Printer, 2012. http://www.doh.gov.za/docs/stratdocs/2012/NSPfull. pdf (accessed 24 September 2013).

19. South African Department of Health. National Health Insurance (NHI) system. Pretoria: Government Printer, 2012. http://www.doh.gov.za/docs/reports/2012/nhiconfrep.pdf (accessed 24 September 2013).

20. South African Department of Health. Framework for the Development and Quarterly Monitoring of the Annual Performance Plans (APPS). Pretoria: Government Printer, 2012. http://www.doh.gov.za/docs/ stratdocs/2012/APPframework.pdf (accessed 26 November 2012).

21. South African Department of Health. eHealth Strategy South Africa 2012-2016. Pretoria: Government Printer, 2012. http://www.doh.gov.za/docs/stratdocs/2012/eHealth_Strategy_South_Africa_2012-2016. pdf (accessed 26 November 2012)

22. World Health Organization. The WHO Mental Health Policy and Service Guidance Package. Geneva: WHO, 2005. http://www.who.int/mental_health/resources/en/Organization.pdf (accessed 26 November 2012)

23. World Health Organization. Suicide Prevention (SUPRE). Geneva: WHO, 2012. http://www.who.int/ mental_health/prevention/suicide/suicideprevent/en/ (accessed 26 November 2012).

24. World Health Organization. Mental Health Gap Action Programme (mhGAP). Geneva: WHO, 2006 http://www.who.int/mental_health/mhgap/en/(accessed 26 November 2012)

25. Moosa MYH, Jeenah FY. Community psychiatry: An audit of the services in southern Gauteng. South African Journal of Psychiatry 2008;14(2):36-43.

26. Alonso-Betancourt O, Morales-Herrera M. Community rehabilitation for schizophrenia patients: Is it feasible in South Africa? South African Journal of Psychiatry 2010;16(3):66-68.

27. Ras J, Koen L, Botha UA, Niehaus DJH. An audit of non-urgent general adult referrals to Stikland State Psychiatric Facility. South African Journal of Psychiatry 2011;17(4):104-107.

28. Moosa MYH, Jeenah FY. A review of the applications for involuntary admissions made to the Mental Health Review Boards by institutions in Gauteng in 2008. South African Journal of Psychiatry 2010;16(4):125-130.

29. Janse van Rensburg B. Applications to Mental Health Review Boards by institutions in Gauteng. (Letter). South African Journal of Psychiatry 2011;17(2):64.

30. Emsley R, Colin F, Flisher AJ, et al. Treatment Guidelines for Psychiatric Disorders. South African Journal of Psychiatry 2013:19(3):128-199. [http://dx.doi.org/10.7196/SAJP.474]

31. Peltzer K, Ramlagan S. Illicit drug use in South Africa: Findings from a 2008 national population based survey. South African Journal of Psychiatry 2010;16(1):8-15.

32. Koen L, Jonathan R, Niehaus DJH. Cannabis use and abuse correlates in a homogeneous South African schizophrenia population. South African Journal of Psychiatry 2009;15(1):8-12.

33. Peltzer K, Phaswana-Mafuya N. Cognitive functioning and associated factors in older adults in South Africa. South African Journal of Psychiatry 2012;18(4):157-163. [http://dx.doi.org/10.7196/SAJP.368]

34. Du Toit EH, Kruger JM, Swiegers SM, et al. The profile analysis of attempted-suicide patients referred to Pelonomi Hospital for psychological evaluation and treatment from 1 May 2005 to 30 April 2006. South African Journal of Psychiatry 2008;14(1):20-25.

35. Nakin DCT, Joubert G, Pretorius PJ, Van Vuuren MJV. Evaluation of attempted-suicide management in a rural district of KwaZulu-Natal. South African Journal of Psychiatry 2007;13(2):52-55.

36. Fine G, Alison HC, Van der Westhuizen D, Krüger C. Predicting frequency of suicide attempts of adolescent outpatients at Weskoppies Hospital using clinical and demographic characteristics. South African Journal of Psychiatry 2012;18(1):22-26.

37. Calitz FJW, Veitch M, Verkhovsky A, Nieuwoudt D, Myburg J, Joubert G. The general profile of children and adolescents with major depression referred to the Free State Psychiatric Complex. South African Journal of Psychiatry 2007;13(4):132-136.

38. Paruk, S, Ramlall S, Burns JK. Adolescent-onset psychosis: A 2-year retrospective study of adolescents admitted to a general psychiatric unit. South African Journal of Psychiatry 2009;15(4):86-92. 